\title{
EFFECTS OF A 5-MINUTE CLASSROOM-BASED PHYSICAL ACTIVITY ON ON-TASK BEHAVIOUR AND PHYSICAL ACTIVITY LEVELS
}

\author{
Hrvoje Podnar, Dario Novak, and Ivan Radman \\ Faculty of Kinesiology, University of Zagreb, Zagreb, Croatia
}

Original scientific paper

https://doi.org/10.26582/k.50.2.17

UDC: $796: 37.091 .322$

\begin{abstract}
:
The objective was to explore the effectiveness of a five-minute classroom-based physical activity (5min-Class-PA) to keep student behaviour on task while increasing PA and energy expenditure during school days. The multiple baselines across subjects' design was implemented to assess on-task behaviour during academic lessons (e.g., Mathematics, Science, Language, Art). Observers were blinded to study condition. A quasi-experimental design was implemented to assess PA volume and energy expenditure using SenseWear Armband body monitor (BodyMedia Inc., Pittsburgh, PA, USA). A convenience sample of elementary school pupils (aged 6-10 years) was observed. A total of eight class departments or two class departments per grade (first to fourth) were included by random selection. All pupils from the selected class departments were asked to participate (total 149$)$ and $126(85 \%)$ had no health aberrations and returned parent signed informed agreement on participation. Five-minute PA daily was performed in the middle of a 45 -min academic lesson by imitating video animations projected on the school board for 12 weeks. The aims were to assess on-task behaviour during academic lessons and physical activity volume and energy expenditure during a school day. When the 5min-Class-PA was implemented, initially high on-task behaviour during the first part of the lesson (91.42\% and $94.8 \%$ for 6-8- and 8-10-year-olds, respectively) was not significantly changed after the $5 \mathrm{~min}$-Class-PA. In contrast, when the $5 \mathrm{~min}$-Class-PA was not implemented, on-task behaviour during the second part of the lesson decreased (by 3\% and 4\% for 6-8- and 8-10-year-olds, respectively). After the 5min-Class-PA was systematically introduced, on-task behaviour systematically improved. The results of the implementation of the classroom-based PA also indicated a small, non-significant increase in PA levels and energy expenditure during the school day, but also a non-significant increase in sedentary time. On-task behaviour during academic lessons and daily in-school PA levels can be improved by implementing a 5min-Class-PA programme.
\end{abstract}

Key words: academic achievement, academic behaviour, school-day physical activity, elementary school pupils

\section{Introduction}

Schools represent ideal environments for introducing programmes that can change the trend of physical inactivity among pupils, and numerous organisations support the implementation of a highquality physical education (PE) and the incorporation of physical activity (PA) throughout the school day (Dobbins, Husson, Decorby, \& Larocca, 2013; Donnelly, et al., 2016). Although PE is a compulsory subject in most countries of the world, it is often delivered irregularly and with a contracted schedule and many pupils are not actively participating in it (Dobbins, et al., 2013; Marques, Gómez, Martins, Catunda, \& Sarmento, 2017). Schools often decide to reduce the number of PE classes and other physical activities of the children in order to increase the number of academic classes to improve test scores (Donnelly, et al., 2016; Marques, et al., 2017; Rasberry, et al., 2011). Over recent decades, research findings have revealed that engaging in PA leads to the enhancement of cognition and better brain functioning, thereby potentially improving the academic performance of students (Donnelly, et al., 2016). However, there is still some scepticism towards regular inclusion of PA in the classroom. Simultaneously, levels of PA among children are declining; they are spending more time participating in sedentary activities, although only a limited number of studies have evaluated the PA levels of pupils during the course of a school day 
(Watson, Timperio, Brown, Best, \& Hesketh, 2017). This is especially important since children spend most of weekday time in school, five days a week, and stay in school for most of their childhood and teenage years.

Research findings suggest the importance of finding new ways of promotion and encouragement of regular PA and its integration in the school day. Classroom-based physical activities may be an effective way of encouraging in-school PA of pupils (da Cruz, 2017; Rasberry, et al., 2011; Watson, et al., 2017). Recent data have indicated a $2 \%$ to $16 \%$ in moderate- to vigorous-intensity PA during intervention lessons and a $2-12 \%$ increase in a school-day moderate- to vigorous-intensity PA (Watson, et al., 2017). However, more research is needed to document the positive relationship between in-school physical activities and indicators of academic performance, i.e., cognitive skills and attitudes, academic behaviours and academic achievements (Marques, et al., 2017; Rasberry, et al., 2011; Watson, et al. 2017). Physical activity is an important factor in achieving an optimal health status and in decreasing the risk of many diseases (Warburton \& Bredin, 2016). Studies on the effects of school-based PA (e.g., during recess, in a classroom, during PE classes or extracurricular programmes) on the indicators of academic performance have showed an even distribution between finding a positive relationship and no significant relationship with a few studies demonstrating a negative relationship (Alvarez-Bueno, et al., 2017; da Cruz, 2017; Donnelly, et al., 2016; Marques, et al., 2017; Rasberry, et al., 2011; Watson, et al., 2017).

Physical inactivity of the younger generation is increasing and opportunities to be physically active in school are reduced. Simultaneously, more time is allocated for improving pupils' academic achievements, e.g., test scores. Classroom-based PA may be an effective way of improving academic performance and, at the same time, of providing an increase in the in-school physical activity. Existing research is inconclusive regarding the type of activity to implement and how to most effectively incorporate PA within the school day (Donnelly, et al., 2016). In response, the current study aims to investigate the effects of Brain Breaks ${ }^{\circledR}$ Physical Activity Solutions by HOPSports ${ }^{\circledR}$ (HopSports, 2018) using blinded observation and the objective assessment of PA levels. Previous research has confirmed the positive effects of Brain Breaks ${ }^{\circledR}$ Physical Activity Solutions on self-efficacy in learning using video exercises (Glapa, et al., 2018) as well as on attitudes and motivation towards physical activity (Popeska, et al., 2018), but analysis of its impacts on academic performance and objectively measured physical activity remains absent. Therefore, the current study investigates the effects of a five-minute classroom-based physical activity on an indicator of academic performance (on-task behaviour) as well as on PA levels and energy expenditure during the school day.

\section{Methods}

\section{Participants}

Out of 149 invited elementary school pupils from first to fourth grade (6-10-year-old), 126 (85\%) had no health aberrations and their parents signed the written informed consent to participate in the study (Figure 1). Based on the statistical error of $5 \%$, statistical power of $80 \%$, constant value $(\mathrm{k})$ of 7.9 and effect size of 0.6 (Mahar, et al., 2006) using formula: $\mathrm{n}=2 / \mathrm{d}^{2} \mathrm{x}$ k $\alpha$,power, the estimated minimal sample size is 44 participants. Two class departments per grade were randomly chosen to be included in the study (eight class departments in total). Within each grade, the experimental and control class departments were randomly selected. Randomization process was conducted by the independent researcher who did not participate in any other segments of this study using computer-generated random numbers. The study was approved by the Committee for Scientific Research and Ethics at the Faculty of Kinesiology, University of Zagreb.

\section{Intervention}

During the intervention period, teachers conducted a 5-minute classroom-based PA (5minClass-PA) on a daily basis at the middle of a 45 -minute academic lesson $\left(20^{\text {th }}-25^{\text {th }}\right.$ minute) using the Brain Breaks ${ }^{\circledR}$ Physical Activity Solutions by HOPSports ${ }^{\circledR}$ (HopSports, 2018), a multimediaand technology-based classroom-based physical activity. Pupils performed a variety of aerobic, strengthening and stretching activities by imitating video animations projected on the white board. The remaining time of the academic lesson during the intervention period and the entire academic lesson during baseline was conducted according to the curriculum of the subject in question.

Prior to the experiment's execution, teachers were provided with guidance and supporting materials on performing the 5min-Class-PA in their classrooms.

\section{Assessment of on-task behaviour}

Effects of 5min-Class-PA on on-task behaviour were determined using multiple baselines across subjects design. The design assumes different groups of participants start the intervention at different time points from the start of the observation. Data acquisition lasted 12 weeks and began with the start of the second school term (JanuaryApril 2014) (Figure 2.).

Each 45-minute academic lesson was recorded using an HD video camera. By reviewing the video, observers assessed pupils' on-task behaviour for 


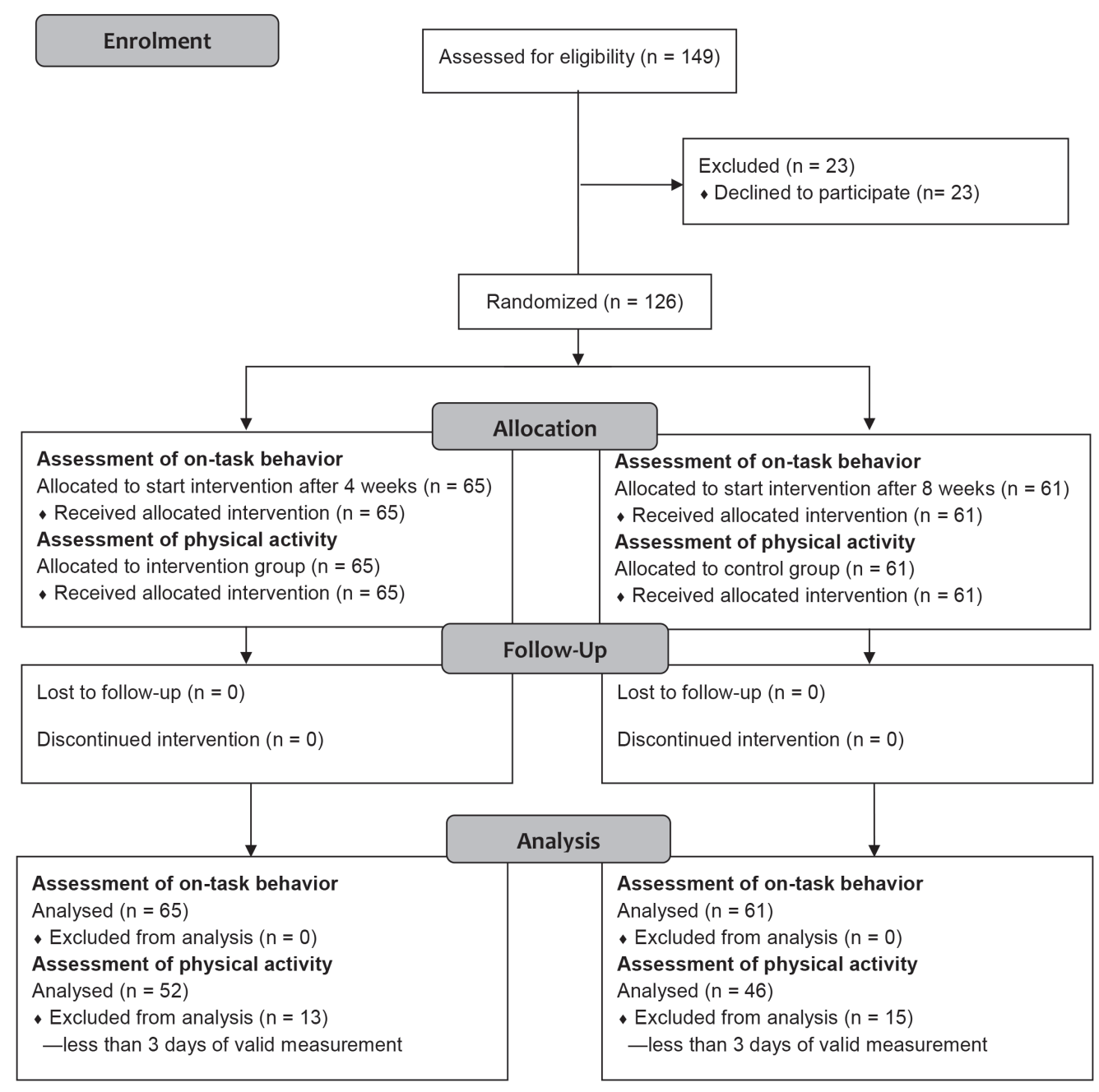

Figure 1. Participants flow diagram

\begin{tabular}{c|c|c|c|c|c|c|c|c|c|c|c|c}
\hline $\begin{array}{c}\text { class/ } \\
\text { wk }\end{array}$ & 1 & 2 & 3 & 4 & 5 & 6 & 7 & 8 & 9 & 10 & 11 & 12 \\
\hline $1 \mathrm{a}$ & & & & & & & & & & & & \\
\hline $2 \mathrm{~b}$ & & & & & & & & & & & & \\
\hline $3 \mathrm{~b}$ & & & & & & & & & & & & \\
\hline $4 \mathrm{~b}$ & & & & & & & & & & & & \\
\hline $1 \mathrm{~b}$ & & & & & & & & & & & & \\
\hline $2 \mathrm{c}$ & & & & & & & & & & & & \\
\hline $3 a$ & & & & & & & & & & & & \\
\hline $4 a$ & & & & & & & & & & & & \\
\hline 4
\end{tabular}

Note: Non-shadowed parts represent the baseline period (no intervention) and shadowed parts represent the intervention period.

Figure 2. Timetable of assessment of the pupils' on-task behavior

16 minutes during the first part and for 16 minutes during the second part of the academic lesson $\left(3^{\text {rd }}\right.$ $19^{\text {th }}$ minute and $26^{\text {th }}-42^{\text {nd }}$ minute). During the baseline (i.e., non-intervention period), the same observation protocol was used, and teachers did not stop academic lessons at any time (Mahar, et al., 2006).
Two observers were trained for the assessment of on-task behaviour. On-task behaviour is a verbal or motor behaviour that is following the class rules and is appropriate to the learning situation. It refers to "children's classroom skills including the ability to work independently and to attend to teacher directed activities," and also includes "student behaviour such as eye contact with the teacher, working quietly, and appropriately orienting to a task" (Clare, Jenson, \& Bray, 2000). Off-task behaviour, on the other hand, is any behaviour that is not on-task and can be motor, acoustic and/or passive, or any other. The training continued until the index of reliability between the observers, expressed in Cohen's kappa, was at least 0.7.

The observers were blinded by editing of the video recording. The video showed only 16 minutes of the first part and 16 minutes of the second part of the academic lesson, so the observers did not know whether pupils had participated in any classroom-based PA or not. During the study there was a very good agreement between the two observers' judgments, $\kappa=.790$ (95\% CI, .774 to .806 ), $\mathrm{p}<.0005$. Assessment lists were used to register the presence or absence of on-task behaviour. Pupils were 
observed in the same order during both 16-minute periods. The pupils that were observed and the order of observation were randomly selected. Video recordings were edited so that they included guidelines to the observers as to when to observe and when to record. By watching the video, the observers observed on-task behaviour in intervals of 10 seconds. After every 10 seconds, they had five seconds to register the observed behaviour of the pupil (either on-task or off-task) on the assessment list. After one minute of observation, the observer rotated to the next pupil. The rotation from a pupil to a pupil was repeated four times, or for 16 observation intervals. One session of watching the video allowed for the observation of four pupils. For a given lesson, a pupil's score for a particular condition (the observation during the first and the second 16-minute periods) was an average percentage. It was calculated by summing up the number of intervals in which each behaviour occurred during the total of a 4-minute observation period, divided by the total number of intervals (i.e., 16), and then multiplied by 100 .

Additionally, four average values of on-task behaviour were calculated separately for all classes $(\mathrm{n}=8)$. Mean on-task behaviour was calculated for the first and the second 16 minutes during both the baseline and the intervention period (averaged across all the baseline or intervention weeks) separately for the 6-8- and 8-10-year-old pupils. In order to compare the groups, the overall mean on-task behaviour of all students was combined over all the baseline or intervention weeks. Mean on-task behaviour during an entire academic lesson was separately calculated for the classes $(n=4)$ that started the intervention after four weeks and for those that started after eight weeks $(n=4)$. Mean on-task behaviour was calculated for week 1-4, 5-8 and 9-12 separately for the 6-8- and 8-10-year-old pupils.

\section{Assessment of physical activity}

The effects of the 5min-Class-PA on PA levels and energy expenditure were assessed for eight weeks using a quasi-experimental design with a control group of standard treatment and measurements taken before and after the intervention. The initial state of PA levels and energy expenditure during the school day was assessed during the first four weeks of the second school term (JanuaryMarch) in the morning hours. Pupils wore a SenseWear Armband instrument (SWA-BodyMedia Inc., Pittsburgh, PA, USA) for five days per week. The SenseWear Armband instrument has been described in Soric and Misigoj-Durakovic (2010). Pupils from the same class wore the instrument during the same week. The week in which each class wore the instrument was randomly selected. Only data on physical activity levels and energy expenditure during the school day (8:00-12:15) were used.

At the beginning of the fifth week, the experimental classes $(n=4)$ started with the intervention, and the effects of the 5min-Class-PA on PA levels and energy expenditure were being determined throughout the intervention period following the same procedure as for the initial state.

During the school day (8:00-12:15), pupils wore the SenseWear Armband instrument for an average of $98.85 \%$ of the time $(93.33-100 \%)$. Trost et al. (2002) reported that, with children, at least three days of monitoring were needed to provide reliable activity data. Therefore, the pupils failing to provide a minimum of three separate days of valid recording were excluded from the study. On average, students wore the SenseWear Armband instrument 4.4 days per week.

The data from all the sensors were averaged over 1-minute periods, and these data were stored in the device's memory and subsequently downloaded to a computer. For the analysis of data obtained by the SWA device, the most recent child-specific exercise algorithms were used (SenseWear Professional software version 6.1; BodyMedia Inc.). The outcome variables were: total daily energy expenditure (TEE), expressed in kilocalories (kcal), daily steps count (STEPS), and the duration of PA performed at various intensities. The intensity was described as metabolic equivalents (METs). A total daily PA duration (PAD) was described as PA requiring more than 4 METs, time spent in less than 4 METs PA was classified as a sedentary PA (SEDENTARY), time spent in 4-5.9 METs PA was classified as a moderate PA (MODERATE), while time spent in $\geq 6$ METs PA was classified as a vigorous physical activity (VIGOROUS). The thresholds of 4.0 and 6.0 METs have frequently been used in defining physical activity intensity in children (Janssen \& Leblanc, 2010).

\section{Statistical analysis}

Wilcoxon signed-rank was used to measure the statistical difference between the two 16-minute periods. On the other hand, the Mann-Whitney U-test was used to measure statistical difference between the baseline and intervention periods. The Kruskal-Wallis test was conducted to determine the existence of any differences at various time points during the 12-week observational period. One-way ANOVA and Tukey's post-hoc tests were conducted to determine whether the values of TEE, STEPS, PAD, SEDENTARY, MODERATE, VIGOROUS and MET scores achieved during the five-minute PA differed between the grade levels. Welch's ANOVA and Games-Howell post-hoc tests were used when the assumption of homogeneity was violated. ANCOVA was performed to determine the effect of the intervention on the post-interven- 
tion outcomes after controlling for age, gender and pre-intervention results.

\section{Results}

\section{Descriptive statistics of $5 \mathrm{~min}$-Class-PA}

TEE increased during the 5min-Class-PA with grade level from first grade $(10.69 \pm 1.71)$, to second grade $(15.11 \pm 2.71)$, to third grade $(15.06 \pm 2.62)$ to fourth grade $(17.69 \pm 5.18)$ and was significantly different between grade levels, Welch's $\mathrm{F}(3.23 .635)=15.427, \mathrm{p}<.001$. The mean STEPS scores were higher for first grade $(433.21 \pm 65.04)$ and second grade $(507.4 \pm 60.12)$ than third grade (369.55 \pm 40.62$)$ and fourth grade $(387.75 \pm 53.46)$ and were significantly different between grade levels, $\mathrm{F}(3.46)=15.322, \mathrm{p}<.001$. MODERATE scores were higher in first grade $(3.08 \pm 0.65)$ and second grade (3.34 \pm 0.93$)$ compared to third grade $(2.32 \pm 0.59)$ and fourth grade $(2.46 \pm 0.74)$ and were significantly different between grade levels, $\mathrm{F}(3.46)=5.298$, $\mathrm{p}=.003$. MET scores showed that the students engaged in moderate intensity PA similar for all grades - first grade $(4.69 \pm 0.53)$, second grade ( $4.84 \pm 0.58)$, third grade $(4.48 \pm 0.46)$ and fourth grade (4.37 \pm 0.59$)$, with no significant difference between the groups, $F(3.46)=1.957, p=.134$ (Table 1).

Because the 5min-Class-PA had different effects on physical activity levels during the activity for 6-8- and 8-10-year-old pupils, it could be assumed that its effects on on-task behaviour and daily PA might also be different. Hence, all subsequent effect analyses of 5min-Class-PA were performed separately for the 6-8-and 8-10-year-old pupils.

\section{Effects of 5min-Class-PA on on-task behaviour}

During both the baseline and intervention periods, the average on-task behaviour of both age groups was high (6-8-year-olds $>85 \%$; 8 - 10 -yearolds $>89 \%$ ). During baseline, the median on-task behaviour decreased (in 6-8-year-olds by $-2.03 \%$; $8-10$-year-olds by $-2.01 \%$ ) from the first to the second 16-minute observation period (in 6-8-yearolds from $88.79 \%$ to $85.12 \%$; in 8-10-year-olds from $94.14 \%$ to $89.83 \%$ ), but the difference was significant only for the 8-10-year-old pupils ( $\mathrm{z}=-3.126$, $\mathrm{p}=.002$; Table 2). During the intervention, the median on-task behaviour slightly increased $(1.64 \%)$ for the 6-8-year-old pupils, whereas for the $8-10$-year old pupils it slightly decreased $(-2,71 \%)$ from the first to the second 16-minute period (in 6-8-year-olds from $91.42 \%$ to $94.32 \%$; in 8 - 10 -yearolds from $94.8 \%$ to $92.09 \%$ ), but the difference was not significant $(6-8$-year-olds $1.64, \mathrm{z}=1.635, \mathrm{p}=.102$; 8 -10-year-olds $-.87, \mathrm{z}=-1.379, \mathrm{p}=.162$; Table 2).

The median on-task behaviour score during baseline (6-8-year-olds $88.79 \%$; 8-10-year-olds 94.14\%) and intervention (6-8-year-olds $91.42 \%$; 8 -10-year-olds $94.8 \%$ ) for the first 16-minute

Table 1. Estimated total energy expenditure and estimated physical activity during a 5-minute classroom-based physical activity

\begin{tabular}{|c|c|c|c|c|c|c|c|}
\hline & $\begin{array}{c}1^{\text {st }} \text { grade } \\
(6-7 \text { years })\end{array}$ & $\begin{array}{c}2^{\text {nd }} \text { grade } \\
\text { (7-8 years) }\end{array}$ & $\begin{array}{c}3^{\text {rd }} \text { grade } \\
(8-9 \text { years })\end{array}$ & $\begin{array}{c}4^{\text {th }} \text { grade } \\
(9-10 \text { years })\end{array}$ & TOTAL & $\mathrm{F}$ & $p$ \\
\hline TEE & $10.69 \pm 1.71^{a, d, f}$ & $15.11 \pm 2.71$ & $15.06 \pm 2.62$ & $17.69 \pm 5.18$ & $14.57 \pm 4.08$ & $15.427^{\mathrm{w}}$ & .001 \\
\hline STEPS & $433.21 \pm 65.04$ & $507.4 \pm 60.12^{\mathrm{a}, \mathrm{b}, \mathrm{e}}$ & $369.55 \pm 40.62^{f}$ & $387.75 \pm 53.46$ & $429.07 \pm 77.1$ & 15.322 & .001 \\
\hline PAD & $4.03 \pm 0.8$ & $4.69 \pm 0.49^{b, c}$ & $3.38 \pm 0.57$ & $3.42 \pm 1.3$ & $3.93 \pm 0.98$ & $12.979 w$ & .001 \\
\hline SEDENTARY & $1.74 \pm 0.68$ & $1.23 \pm 0.49^{b}$ & $2.47 \pm 0.75$ & $2.32 \pm 1.34$ & $1.89 \pm 0.97$ & $8.496^{w}$ & .001 \\
\hline MODERATE & $3.08 \pm 0.65$ & $3.34 \pm 0.93^{\mathrm{b}, \mathrm{e}}$ & $2.32 \pm 0.59$ & $2.46 \pm 0.74$ & $2.84 \pm 0.84$ & 5.298 & .003 \\
\hline VIGOROUS & $0.95 \pm 0.74$ & $1.09 \pm 1.07$ & $0.97 \pm 0.51$ & $0.66 \pm 0.59$ & $0.92 \pm 0.77$ & .688 & .564 \\
\hline MET & $4.69 \pm 0.53$ & $4.84 \pm 0.58$ & $4.48 \pm 0.46$ & $4.37 \pm 0.59$ & $4.61 \pm 0.56$ & 1.957 & .134 \\
\hline
\end{tabular}

Note. a first vs. second grade at $p<.05 ;{ }^{b}$ second vs. third grade at $p<.05 ;{ }^{c}$ third vs. fourth grade at $p<.05 ;{ }^{d}$ first vs. fourth grade at $p<.05$; e second vs. fourth grade at $p<.05,{ }^{f}$ first vs. third grade at $p<.05 ;{ }^{w}$ Robust Tests of Equality of Means - Welch. TEE - total daily energy expenditure, expressed as kilocalories (kcal); STEPS - daily steps count; PAD - total daily physical activity duration, described as PA requiring more than 4 METs; SEDENTARY - time spent in PA requiring less than 4 METs is classified as sedentary physical activity; MODERATE - time spent in PA requiring 4-5.9 METs is classified as moderate physical activity; VIGOROUS - time spent in PA requiring $\geq 6$ METs is classified as vigorous physical activity; PA intensity is described as metabolic equivalents (METs).

Table 2. Median difference in on-task behaviour between the first and the second 16-minute observation periods

\begin{tabular}{llccccc}
\hline & & First 16 min & Second 16 min & $2^{\text {nd }-1 \text { st }}$ & z & $\mathrm{p}$ \\
\hline \multirow{2}{*}{ 6-8-year-olds } & Baseline period & 88.79 & 85.12 & -2.03 &,- 778 & .437 \\
& Intervention period & 91.42 & 94.32 & 1.64 & 1.635 & .102 \\
\multirow{3}{*}{ 8-10-year-olds } & Baseline period & 94.14 & 89.83 & -2.01 & $\mathbf{- 3 . 1 2 6}$ & .002 \\
& Intervention period & 94.8 & 92.09 &,- 87 & -1.379 & .162 \\
\hline
\end{tabular}

Note. Data presented are grouped median scores; first $16 \mathrm{~min}$ and second $16 \mathrm{~min}$ are observation periods between $3^{\text {rd }}-19^{\text {th }}$ minute and the $26^{\text {th }}-42^{\text {th }}$ minute of a 45 -minute lesson, respectively. 
observation period was not significantly different (6-8-year-olds $U=10.763, z=.764, p=.445 ; 8$-10-yearolds $\mathrm{U}=18.698, \mathrm{z}=.259, \mathrm{p}=.796$ ). However, the median on-task behaviour score for the second 16-minute observation period was significantly higher $(\mathrm{U}=12.489, \mathrm{z}=3.287, \mathrm{p}=.001)$ during the intervention (94.32\%) compared to the baseline (85.12\%) period for the 6-8-year-old pupils. Similarly, the median on-task behaviour score for the second 16-minute observation period for the 8-10-yearold pupils was also higher during the intervention $(92.09 \%)$ compared to the baseline $(89.83 \%)$ period, but the difference was not significant ( $\mathrm{U}=19.247$, $\mathrm{z}=.778, \mathrm{p}=.437$; Table 3).

The 6-8-year-old pupils' on-task behaviour was significantly different at different time points during the 12-week observational period for both the classes that started the intervention after four weeks, $\chi^{2}(2)=18.059, p<.001$, and those that started the intervention after eight weeks, $\chi^{2}(2)=13.782$, $\mathrm{p}=.001$ (Table 4). The post-hoc analysis revealed significant differences in on-task behaviour for the classes that started the intervention after four weeks from week 1-4 (77.5\%) to week 5-8 (89.69\%; $\mathrm{p}=.027)$ and to week $9-12(88.77 \% ; \mathrm{p}<.001)$, but not from week 5-8 to week 9-12 ( $p=.472)$. For the classes that started the intervention after eight weeks, the post$h o c$ analysis revealed non-significant differences in on-task behaviour from week 1-4 (92.19\%) to week $5-8(92.58 \% ; p>.99)$, but the significant differences from week 1-4 $(92.19 \%)(\mathrm{p}=.003)$ and 5-8 $(92.58 \%$; $\mathrm{p}<.031)$ to week 9-12 (97.32\%).

On-task behaviour of 8-10-year-old pupils was significantly different at different time points during the 12-week observational period for the classes that started the intervention after four weeks, $\chi^{2}(2)=14.945, p=.001$, but not for the classes that started the intervention after eight weeks, $\chi^{2}(2)=5.041, p=.080$ (Table 4). The post-hoc analysis revealed the significant differences in on-task behaviour for the classes that started the intervention after four weeks from week 1-4 (83.81\%) to week 5-8 $(92.55 \% ; \mathrm{p}=.001)$ and to week $9-12$ $(91.52 \% ; \mathrm{p}<.040)$, but not from week $5-8$ to week $9-12(\mathrm{p}=.752)$.

\section{Effects of 5min-Class-PA on PA levels}

After controlling for age, gender and pre-intervention results, no statistically significant differences were identified in: $\operatorname{TEE}(1.97)=2.249, \mathrm{p}=.137$; STEPS $(1.97)=.838, \mathrm{p}=.362$; PAD $(1.97)=.003$, $\mathrm{p}=.957$; SEDENTARY $(1.97)=.069, \mathrm{p}=408$; MODERATE (1.92) $=.000, \mathrm{p}=.999$; VIGOROUS $(1.92)=.074, \mathrm{p}=786$; METs (1.92)=.423, $\mathrm{p}=.517$. Although not significant, the intervention group displayed a higher TEE (baseline 257.88 \pm 10.57 vs. intervention $281.79 \pm 11.85$ ), STEPS (baseline $2717.51 \pm 109.55$ vs. intervention $2868.79 \pm 122.87$ ) and VIGOROUS time (baseline $6.79 \pm 1.05$ vs. intervention $7.224 \pm 1.18$ ), but also a higher SEDENTARY time (baseline $177.46 \pm 3.28$ vs. intervention 181.59 \pm 3.68 ) (Table 5).

\section{Discussion and conclusions}

In the present study, PA levels and energy expenditure of 6-10-year-old pupils were measured during their classroom-based PA and the school day. Similar studies investigating the effects of classroom-based PA used a variety of measures to assess PA (Watson, et al., 2017). In the current study, body monitors were used that allowed for the

Table 3. Median difference in on-task behaviour between the baseline and the intervention periods

\begin{tabular}{llccccc}
\hline & & Baseline period & Intervention period & $U$ & $z$ & $p$ \\
\hline \multirow{2}{*}{ 6-8-year-olds } & First 16 min & $88.79(140.41)$ & $91.42(147.77)$ & 10.763 & .764 & .445 \\
& Second 16 min & $85.12(126.93)$ & $94.32(158.56)$ & 12.489 & $\mathbf{3 . 2 8 7}$ & .001 \\
\multirow{2}{*}{ 8-10-year-olds } & First 16 min & $94.14(191.11)$ & $94.8(193.89)$ & 18.698 & .259 & .796 \\
& Second 16 min & $89.83(188.25)$ & $92.09(196.75)$ & 19.247 & .778 & .437 \\
\hline
\end{tabular}

Note. Data presented are grouped median scores (mean ranks); the first 16 min and the second 16 min are observation periods between $3^{\text {rd }}-19^{\text {th }}$ minute and $26^{\text {th }}-42^{\text {th }}$ minute of a 45 -minute lesson, respectively.

Table 4. Differences in on-task behaviour during a 12-week observational period

\begin{tabular}{|c|c|c|c|c|c|c|}
\hline & \multirow{2}{*}{$\begin{array}{l}\text { BEGINNING OF THE } \\
\text { INTERVENTION }\end{array}$} & \multicolumn{3}{|c|}{ WEEKS } & \multirow{2}{*}{$\chi^{2}$} & \multirow{2}{*}{$\mathrm{p}$} \\
\hline & & $1-4$ & $5-8$ & $9-12$ & & \\
\hline \multirow{2}{*}{ 6-8-year-olds } & After 4 weeks & $77.5^{\mathrm{a}, \mathrm{b}}$ & 89.69 & 88.77 & 18.059 & .001 \\
\hline & After 8 weeks & 92.19 & 92.58 & $97.32^{b, c}$ & 13.782 & .001 \\
\hline \multirow{2}{*}{ 8-10-year-olds } & After 4 weeks & $83.81^{a, b}$ & 92.55 & 91.52 & 14.945 & .001 \\
\hline & After 8 weeks & 91.59 & 96.96 & 88.02 & 5.041 & .080 \\
\hline
\end{tabular}

Note. Data presented are grouped median scores; during weeks 1-4 there was no intervention, during weeks 5-8 only classes 1 a, $2 \mathrm{~b}, 3 \mathrm{~b}$ and $4 \mathrm{~b}$ ('After 4 weeks') participated in the intervention, and during weeks $9-12$ classes $1 \mathrm{~b}, 2 \mathrm{c}, 3 \mathrm{a}$ and $4 \mathrm{a}$ also started with the intervention ('After 8 weeks'); ${ }^{a} 1-4$ vs. $5-8, p<.05$; ${ }^{b} 1-4$ vs. $9-12, p<.05$; ${ }^{5} 5-8$ vs. $9-12, p<.05$ 
Table 5. Control and intervention adjusted means and variability for the post-intervention outcomes with age, gender and pre-intervention results as a covariate

\begin{tabular}{lcccc}
\hline & $\begin{array}{c}\text { Baseline period } \\
(\mathrm{M} \pm \mathrm{SE})\end{array}$ & $\begin{array}{c}\text { Intervention period } \\
(\mathrm{M} \pm \mathrm{SE})\end{array}$ & $\mathrm{F}$ & $\mathrm{p}$ \\
\hline TEE & $257.88 \pm 10.57$ & $281.79 \pm 11.85$ & 2.249 & .137 \\
STEPS & $2717.51 \pm 109.55$ & $2868.79 \pm 122.87$ & .838 & .362 \\
PAD & $26.03 \pm 2.15$ & $26.21 \pm 2.42$ & .003 & .957 \\
SEDENTARY & $177.46 \pm 3.28$ & $181.59 \pm 3.68$ & .690 & .408 \\
MODERATE & $19.09 \pm 1.48$ & $19.09 \pm 1.664$ & .000 & .999 \\
VIGOROUS & $6.79 \pm 1.05$ & $7.224 \pm 1.18$ & .074 & .786 \\
METS & $2.32 \pm 0.08$ & $2.392 \pm 0.09$ & .423 & .517 \\
\hline
\end{tabular}

Note. $M=$ mean, SE=standard error. TEE - total daily energy expenditure, expressed as kilocalories (kcal); STEPS - daily steps count; PAD - total daily physical activity duration, described as PA requiring more than 4 METs; SEDENTARY - time spent in PA requiring less than 4 METs is classified as sedentary physical activity; MODERATE - time spent in PA requiring 4-5.9 METs is classified as moderate physical activity; VIGOROUS - time spent in PA requiring $\geq 6$ METs is classified as vigorous physical activity; PA intensity is described as metabolic equivalents (METs).

measurement of PA levels and energy expenditure assessment. The results show that pupils engaged in moderate-to-vigorous physical activity. MET levels did not differ between age groups and were 4.61 on average. The pupils aged 6-8 years spent more time in moderate-to-vigorous PA than those aged 8-10 years. They also had a lower sedentary time during the activities. Possibly, the video animations used were more motivating for younger pupils as they included cartoon characters and an environment that is more appealing to younger pupils. Also, it is likely that the classroom teachers' behaviour played an important role in the overall activity level during the PA. Teachers should actively participate in PA and choose video animations based on pupils' preferences.

In terms of the effects of the experiment on on-task behaviour during the second part of the academic lesson, pupils generally achieved a higher level of on-task behaviour after participating in physical activity. On-task behaviour over the first 16 minutes during the baseline and intervention period did not differentiate between the 6-8- and 8-10-yearold pupils. This is consistent with previous research (Jarrett, Maxwell, Dickerson, Hoge, Davies, \& Yetley, 1998; Mahar, et al., 2006) and indicates that pupils will not be more or less on-task when they anticipate a physically active break. During the second 16 minutes of the intervention period, after the pupils' participation in the $5 \mathrm{~min}$-Class-PA, on-task behaviour of the 6-8-year-old pupils was $9 \%$ higher than during the same observational period at baseline. On-task behaviour of the 8-10-year-old pupils was also higher during the second 16 minutes in the intervention period compared to baseline, but this $2 \%$ difference was not significant.

On-task behaviour during the baseline period decreased from the first to the second 16-minute observational period. For the 6-8-year-old pupils, a decrease of $3 \%$ was not significant, but for the $8-10$-year-old pupils there was a $4 \%$ significant decrease in on-task behaviour. This is consistent with previous research indicating that on-task behaviour would expectedly decrease as the length of work time without a break increases (Mahar, et al., 2006) and that children might think and work less efficiently when engaged in long periods of uninterrupted instructional time (Jarrett, et al., 1998; Pellegrini \& Davis, 1993). However, during the intervention period pupils manifested a similar level of on-task behaviour during both observational periods. The initially high on-task behaviour of $91.42 \%$ and $94.8 \%$ for $6-8$ - and $8-10$-year-old pupils, respectively, was not significantly changed after the 5min-Class-PA. Probably, the initially high on-task behaviour made it difficult to achieve a significant increase in it. However, the results show an evident trend of slowing the decrease in on-task behaviour in the second part of the lesson for the 8-10-year-old pupils and even a slight increase of the initially high on-task behaviour by almost $4 \%$ for the 6-8-year-old pupils.

Separate analyses conducted for the pupils who started the intervention after four weeks and those who started it after eight weeks showed that on-task behaviour during the entire academic lesson was significantly different at different time points during the 12-week observational period for the two age groups. The results indicate there is a direct and positive association between having PA systematically implemented into the classrooms and on-task behaviour.

The effects on participants are mainly characterized by on-task behaviour such as their improved assignment completion, organization, planning and impulse control. Due to these positive effects, teachers in general strongly prefer the incorporation of 5min-Class-PA. The practical effects of the experiment allowed teachers to help their pupils cope with academic lessons, which was also favourable to teachers. Hence, this study's results also established that incorporating PA in the classroom could be an aid to educators to fulfil their duties as teachers. 
The results imply that the integration of the classroom-based PA can improve pupil's cognitive functioning. Blair and Diamond (2008) assert that cognitive and behavioural school readiness depends largely on the development of children's executive regulatory systems during the preschool period. Additionally, cognitive capacities such as the ability to sustain attention and monitor one's thoughts also are defining features of self-regulation. In the early childhood classroom, the need for self-regulation is greatest when there is a pause in structured, teacherdirected activities (Cassidy, Buell, Pugh-Hoese, \& Russell, 1995). Self-regulation is important when attempting to achieve a stated goal by means of initiation or completion of a given routine. When failure at usual activities occurs, self-regulation is crucial to maintaining decorum in the classroom.

The results of the implementation of the classroom-based PA also indicate a small, non-significant increase in PA levels and energy expenditure during the school day, but also a non-significant increase in sedentary time. These results suggest that five minutes of PA might not be enough to produce a significant increase in the total daily in-school PA levels. It also suggests that pupils might increase their sedentary behaviour during the rest of the school day if they participate in the classroom-based physical activity. However, it is important to recognize the positive effects of incorporating PA and PE in every academic context. In the past decades, physical activity/education was taken for granted, and sometimes not required to be included in the schools. In contrast to this model, many scholars are advocating the inclusion of PE or even classroom-based physical activity. While there is an incomplete and unbalanced body of empirical knowledge in the literature on the effectiveness of this programme, its influence on individuals, student insights regarding this model, and challenges teachers experience using this model, the advantage of its inclusion in education surpasses its shortcomings, and it thus needs to be strictly adopted nowadays.
The analysis of the impact of PA from these perspectives and the effects on the participants helped in understanding of how such an activity affects students, parents, and teachers. The positive effects of the experiment on the participants matched the impact of incorporating the classroombased PA through an academic perspective in the postmodern era. Reinforcement and promotion of classroom-based physical activities in the current education system enables students to perform better academically (Alvarez-Bueno, et al., 2017) and to improve self-efficacy in learning by a video exercise (Glapa, et al. 2018) as well as attitudes and motivation towards PA (Popeska, et al., 2018). Furthermore, since more parents and teachers want and require their children to stay physically fit, classroom-based physical activities have the capacity to fulfil this by ensuring that children avoid obesity, being overweight, and the risk of chronic diseases (Dobbins, et al., 2013).

The positive effects of the classroom-based PA on academic performance of pupils help account for the growing number of stakeholders reinforcing the incorporation of physical activities inside the classroom, despite its challenges and limitations. Benefits of the classroom-based PA include the following: an increase in physical awareness in schools, improved academic performance, effective transfer of knowledge to pupils, and the proliferation of institutions that offer and reinforce the advantage of incorporating PA and physical education. Overall, the inclusion of physical-based activity programmes in schools creates an ideal environment not just for attaining positive learning results but also for effectively implementing learned ideas in the classroom. It is important to recognize that the positive effects of incorporating classroombased physical activities is an essential concept that can be affected by academic setting changes.

The limitations of the present study are its relatively small sample size and inability to compare participants by known confounders such as socioeconomic status. Future research should also examine the long-term impacts and chronic effects of the classroom-based physical activity.

\section{References}

Alvarez-Bueno, C., Pesce, C., Cavero-Redondo, I., Sanchez-Lopez, M., Garrido-Miguel, M., \& Martinez-Vizcaino, V. (2017). Academic achievement and physical activity: A meta-analysis. Pediatrics, 140(6). doi:10.1542/peds.20171498

Blair, C., \& Diamond, A. (2008). Biological processes in prevention and intervention: The promotion of self-regulation as a means of preventing school failure. Development and Psychopathology, 20(3), 899-911. doi: 10.1017/ S0954579408000436

Cassidy, D.I., Buell, M.I., Pugh-Hoese, S., \& Russell, S. (1995). The effect of education on child care teachers' beliefs and classroom quality: Year one evaluation of the TEACH early childhood associate degree scholarship program. Early Childhood Research Quarterly, 10(2), 171-183. doi: 10.1016/0885-2006(95)90002-0

Clare, S., Jenson, W., \& Bray, M. (2006). Self-modeling as a treatment for increasing on-task behavior. Psychology in the Schools, 37(6), 517-522. doi: 10.1002/1520-6807(200011)37:6<517::AID-PITS4>3.0.CO;2-Y 
da Cruz, K. (2017). Supporting positive school outcomes through school-based physical activity intervention: Current evidence and resources. Intervention in School and Clinic, 53(2), 120-125. doi:10.1177/1053451217693361

Dobbins, M., Husson, H., Decorby, K., \& Larocca, R.L. (2013). School-based physical activity programs for promoting physical activity and fitness in children and adolescents aged 6 to 18. The Cochrane Database of Systematic Reviews, 2, Art. No. CD007651. doi: 10.1002/14651858.CD007651.pub2

Donnelly, J.E., Hillman, C.H., Castelli, D., Etnier, J.L., Lee, S., Tomporowski, P., Lambourne, K. \& Szabo-Reed, A.N. (2016). Physical activity, fitness, cognitive function, and academic achievement in children: A systematic review. Medicine and Science in Sports and Exercise, 48(6), 1197-1222. doi:10.1249/MSS.0000000000000901

Glapa, A., Grzesiak, J., Laudanska-Krzeminska, I., Chin, M.-K., Edginton, C.R., Mok, M.M.C., \& Bronikowski, M. (2018). The impact of Brain Breaks classroom-based physical activities on attitudes toward physical activity in Polish school children in third to fifth grade. International Journal of Environmental Research and Public Health, 15(2), 368. doi:10.3390/ijerph15020368

HopSports website. (2018). Interactive Youth Physical Education Training System. Retrieved on September 10, 2018 from: http://hopsports.com/what-is-brain-breaks

Janssen, I., \& Leblanc, A.G. (2010). Systematic review of the health benefits of physical activity and fitness in schoolaged children and youth. International Journal of Behavioral Nutrition and Physical Activity, 7, 40. doi: $10.1186 / 1479-5868-7-40$

Jarrett, O.S., Maxwell, D.M., Dickerson, C., Hoge, P., Davies, G., \& Yetley, A. (1998). Impact of recess on classroom behavior: Group effects and individual differences. International Journal of Educational Research, 92(2), 121-126. doi: 10.1080/00220679809597584

Mahar, M.T., Murphy, S.K., Rowe, D.A., Golden, J., Shields, A.T. \& Raedeke, T.D. (2006). Effects of a classroombased program on physical activity and on-task behaviour. Medicine and Science in Sports and Exercise, 38(12), 2086-2094. doi: 10.1249/01.mss.0000235359.16685.a3

Marques, A., Gómez, F., Martins, J., Catunda, R., \& Sarmento, H. (2017). Association between physical education, school-based physical activity, and academic performance: A systematic review. Retos, 31, 316-320.

Pellegrini, A.D., \& Davis, P.D. (1993). Relations between children's playground and classroom behaviour. British Journal of Educational Psychology, 63(Pt 1), 88-95. doi: 10.1111/j.2044-8279.1993.tb01043.x

Popeska, B., Jovanova-Mitkovska, S., Chin, M.-K., Edginton, C.R., Mok, M.M.C., \& Gontarev, S. (2018). Implementation of Brain Breaks ${ }^{\circledR}$ in the classroom and effects on attitudes toward physical activity in a Macedonian school setting. International Journal of Environmental Research and Public Health, 15(6), 1127. doi:10.3390/ijerph15061127

Rasberry, C.N., Lee, S.M., Robin, L., Laris, B.A., Russell, L.A., Coyle, K.K. \& Nihiser, A.J. (2011). The association between school-based physical activity, including physical education, and academic performance: A systematic review of the literature. Preventive Medicine, 52(Suppl 1), S10-S20. doi: 10.1016/j.ypmed.2011.01.027

Soric, M., \& Misigoj-Durakovic, M. (2010). Physical activity levels and estimated energy expenditure in overweight and normal-weight 11-year-old children. Acta Paediatrica, 99(2), 244-250. doi: 10.1111/j.1651-2227.2009.01553.x

Trost, S.G., Pate, R.R., Sallis, J.F., Freedson, P.S., Taylor, W.C., Dowda, M. \& Sirard, J. (2002). Age and gender differences in objectively measured physical activity in youth. Medicine and Science in Sports and Exercise, 34(2), 350-355. doi: 10.1097/00005768-200202000-00025

Warburton, D.E.R., \& Bredin, S.S.D. (2016). Reflections on physical activity and health: What should we recommend? Canadian Journal of Cardiology, 32(4), 495-504. doi:10.1016/j.cjca.2016.01.024

Watson, A., Timperio, A., Brown, H., Best, K., \& Hesketh, K.D. (2017). Effect of classroom-based physical activity interventions on academic and physical activity outcomes: A systematic review and meta-analysis. International Journal of Behavioral Nutrition and Physical Activity, 14(1), 114. doi:10.1186/s12966-017-0569-9

Submitted: January 26, 2018

Accepted: October 9, 2018

Published Online First: December 7, 2018
Correspondence to:

Hrvoje Podnar, Ph.D.

Postdoctoral Fellow

University of Zagreb, Faculty of Kinesiology

Department of General and Applied Kinesiology

Horvacanski zavoj 15, 10000 Zagreb, Croatia

Phone: +385(0)915825070

E-mail: hrvoje.podnar@kif.hr

\section{Acknowledgment}

Immeasurable appreciation and deepest gratitude for the help and support are extended to the following persons who in many different ways have contributed in making this publication possible: Tom Root and Ming-kai Chin of the HOPSports, Inc. for supporting the use of Brain Breaks ${ }^{\circledR}$ Physical Activity Solutions in order to complete the studies on which this publication is based. Marjeta Mišigoj-Duraković and Maroje Sorić of the Department of Kinesiological Anthropology and Methodology at the Faculty of Kinesiology, University of Zagreb for lending their equipment and tactical execution support. Special thanks are extended to the teachers and students of the Ivo Andrić Elementary School in Zagreb who took part in this study and generously shared their time and ideas. 